\title{
Electrometric Investigation of the Nature and Stability of Mixed Ligand Complexes of L-Ornithine and 1,10-Phenanthroline with Some Essential Metal lons in Aqua-TBAB or PEG-400 Surfactant
}

\author{
Atnafu Guadie Assefa ( $\square$ atnafuguad@gmail.com ) \\ University of Gondar \\ Molla Tefera Negash \\ University of Gondar \\ Mulugeta Legesse Akele \\ University of Gondar \\ Bewketu Mehari Workneh \\ University of Gondar \\ Ayal Adugna Mesfin \\ University of Gondar \\ Pulipaka Shyamala \\ Andhra University \\ Gollapalli Nageswara Rao \\ Andhra University
}

Research Article

Keywords: Bioavailability, Essential Metals, Mixed Ligand Complex, TBAB and PEG-400, Surfactants

Posted Date: July 22nd, 2021

DOI: https://doi.org/10.21203/rs.3.rs-701586/v1

License: (c) (i) This work is licensed under a Creative Commons Attribution 4.0 International License. Read Full License 


\section{Abstract \\ Background}

Despite the availability of information about the effect of aqua-surfactants media on the stability of binary complexes, data related to mixed ligand complexes of Phen and Orn with essential metals in aqua-surfactant medium is scarce. The aim of this study was, to determine the stabilities of the mixed ligand complexes of essential metal ions $\left(\mathrm{Co}^{2+}, \mathrm{Ni}^{2+}, \mathrm{Cu}^{2+}\right)$ with Phen and Orn in aqua-TBAB and PEG-400 surfactants with an eye on the prediction of the bioavailability of the metal complexes.

\section{Results}

Complexes of some essential metal $(\mathrm{M})$ ions $\left(\mathrm{Co}^{2+}, \mathrm{Ni}^{2+}, \mathrm{Cu}^{2+}\right)$ of $\mathrm{L}$-ornithine $(\mathrm{L})$ and 1,10-phenanthroline $(\mathrm{X})$ ligands in various concentrations $(0.0-2.5 \% \mathrm{v} / \mathrm{v}$ ) of aqueous tetrabutylammonium bromide (TBAB) or polyethylene glycol-400 (PEG-400) surfactant were synthesized pH-metrically at $298 \mathrm{~K}_{\text {and }} 0.16 \mathrm{~mol} \mathrm{~L}^{-1}$ ionic strength. The relative amounts of L:M:X were 2.5:1.0:2.5; 5.0:1.0:2.5; 2.5:1.0:5.0. The data acquisition of acid-base equilibria and determination of stability constants were performed using MINIQUAD75 algorithm. The distribution patterns of the complexes with varying $\mathrm{pH}$ and compositions of surfactants were presented from the plots of SIM run data.

\section{Conclusions}

The best fit chemical models were found to be $M L X H, M L X{ }_{2} \mathrm{H}$ in the lower $\mathrm{pH}$, and $M L X, M L_{2} \mathrm{X}$ in the higher $\mathrm{pH}$ ranges for all the metals. The logged values of stability constants decreased linearly with increasing concentrations of surfactants, indicating the dominance of electrostatic factors. The log of the disproportionation constant and the change in log values of the mixed ligand constant indicated additional stability of the mixed ligand complexes, compared to the parent binary complexes due to interactions outside the coordination sphere. This makes the mixed ligand complexes more amenable to metal ion storage and transport and threw light to have information on the less stable binary complexes easily bioavailability while the mixed ligand complexes could be stored and transported in the bio-fluids. Significant change on the magnitudes of the stability constants, high values of standard deviation and rejection of some of the proposed chemical models were observed due to pessimistic error, indicating the sufficiency of the models to represent the data and accuracy of the method employed.

\section{Introduction}

Metal complexes of biogenic ligands have various applications in solution chemistry, and remain to be hot research themes for many researchers [1-8]. Mononuclear binary complexes involving interaction of single metal with one ligand and mixed ligand complexes that contain more than one ligand have been studied for long time $[9,10]$. The stabilities of the synthesized complexes are a direct function of many factors such as: dielectric constants [11-16], stacking interactions between ligands, and metal-ligands [13-18], and electrostatic and non-electrostatic interactions $[7,9,11-16]$. Literature reports indicated that most of these factors were mainly dependent on the composition of organic solvents, which could alter the dielectric constant of the medium and solvating power of the solvents $[12,15]$. Despite chemical speciation have been exhaustively studied in aqua-organic medium, the synthesis of metal complexes of ligands in aqua-micellar medium has sustained due attention owning to their untouchable applications and versatile altering capacity of the medium in solution chemistry.

1,10-Phenanthroline (Phen) is bidentate hetrocyclic ligand having two electron donor $\mathrm{N}$-atoms to the vacant shell of transition metal ions $[19,20]$. Studies have also revealed that Phen forms both binary and mixed ligand complexes with a number of metal ions in wide $\mathrm{pH}$ ranges [6, 19-22]. It is capable of forming stable metal complexes of even lower oxidation states $[10,23,24]$ in mixed ligand system. Several reports have indicated that Phen metal complexes have varieties of applications. For example, copper complexes of Phen inhibit the proteasome activity housed into tumor cells [25]. Phen complexes of metals were not only synthesized in aqueous solvent, but also in aqua-organic solvents and used as potent photodynamic herbicide modulators $[6,19,22]$.

L-Ornithine (Orn), a tridentate ligand having two associable amino protons and one dissociable carboxylate proton, is capable of forming stable non-protonated metal-ligand complexes with many metal ions in various solvents [26]. Orn complexes of bio-essential metals play an important role in chemotherapeutic applications such as building muscles, reducing body fats, removing toxic ammonia from liver, etc [27]. Recently, groups of authors have published the capability of L-ornithine to form stable mononuclear binary complexes with some 
essential metal ions in surfactant media [26]. The current work of mixed ligand complex of metals is continuation of the protonation and binary complexes of the same ligand and metal ions in the same media.

Phen as bidentate and Orn as tridentate ligands play prominent roles in maintaining the stability of complexes in various solvents [6,21]. Despite the availability of information on the effect of aqua-surfactants on the stability of binary complexes $[19,22,26]$, data related to mixed ligand complexes of Phen and Orn with essential metals in aqua-surfactant medium is scarce. The aim of this study was, therefore, to determine the stabilities of the mixed ligand complexes of some essential metal ions $\left(\mathrm{CO}^{2+}, \mathrm{Ni}^{2+}, \mathrm{Cu}^{2+}\right)$ with Phen and Orn in aqua-TBAB and PEG-400 surfactant media with an eye on the prediction of the bioavailability the metal complexes.

\section{Materials And Methods}

\subsection{Chemicals and Solutions}

All solutions were prepared in triply distilled water free of dissolved gases by nitrogen gas purged in it. Solutions of $0.05 \mathrm{~mol} \mathrm{dm}^{-3} \mathrm{Orn}$ and Phen (Sigma-Aldrich, India), $0.4 \mathrm{~mol} \mathrm{dm}^{-3}$ of $\mathrm{NaOH}$ (Merck, India), $0.2 \mathrm{~mol} \mathrm{dm}^{-3} \mathrm{HCl}$ (Merck, India), $0.5-2.5 \%$ (v/v) surfactants (TBAB and PEG-400) were prepared. Tetrabutylammonium bromide, TBAB (Avra, India) and polyethylene glycol 400, PEG-400 (Merck, India), murexide and fast sulphon black F (both in ALPHA CHEMIKA, India), concentrated ammonia (Mysore Ammonia, India), hexamine, hydroxylamine hydrochloride (Prochem, Inc, Medley, USA), Buffer Solutions ( $\mathrm{pH} 4, \mathrm{pH} 7$ and pH 9; Merck, India) were used as received while $\mathrm{NaOH}$ was washed 3-4 times with double distilled water and discarded prior to its standardization against potassium hydrogen phthalate and Gran-titrated regularly [28] to check the absence of carbonates. Then, $\mathrm{NaOH}$ was used to determine concentration of $\mathrm{HCl}(0.05 \mathrm{~mol}$ $\left.\mathrm{dm}^{-3}\right) . \mathrm{HCl}$ solution was added to the titration mixture to ensure the solubility of the analytes, and suppress hydrolysis $[15-18,29,30]$ of the synthesized complexes. A $2 \mathrm{~mol} \mathrm{dm}^{-3}$ solution of sodium chloride (Merck, India) was prepared to maintain the desired ionic strength $\left(0.16 \mathrm{~mol} \mathrm{dm}^{-3}\right)$ of the titration mixture. Chemicals used in this investigation were of analytical reagent grade.

\subsection{Instruments and Methods of Titrations}

A combined glass electrode of aqueous range conjugated with Metrohm 877 Titrino plus Auto-titrator (Switzerland, readability 0.001) was used to carry out electrometric titrations. Data acquisition was carried out at an ionic strength of $0.16 \mathrm{~mol} \mathrm{dm}^{-3}$ and temperature of $298 \mathrm{~K}$. The steady flow of purified nitrogen gas was applied through the titration mixture [21,26,31]. Periodic calibration of the electrode was done to ensure reliable measurement under stable and reproducible response. The electrode had been checked for its stable response through careful equilibration in well stirred TBAB or PEG-400 solutions. Then, free strong acid titration $(\mathrm{HCl})$ with strong base $(\mathrm{NaOH})$ was carried out from which correction factor could be calculated using MINIQUAD75 algorithm. The values of the correction factor were used as probe in calculating stability constants of the complexes. The titration of metal-ligand mixtures in various concentrations of aquaTBAB or aqua-PEG-400 surfactant solutions $(0.0,0.5,1.0,1.5,2.0$ and $2.5 \% \mathrm{v} / \mathrm{v})$ was carried out with $0.4 \mathrm{~mol} \mathrm{~L}^{-1}$ sodium hydroxide. The total titration mixtures were composed of triply distilled water, salt, mineral acid, $1^{\circ}$ ligand, $2^{\circ}$ ligand, metal ion of interest and surfactant media in the given order with total volume of $50.0 \mathrm{~mL}$. Calculation of the volume share of individual components to $50.0 \mathrm{~mL}$ was made based on their contribution to the designed total ionic strength used in this study $\left(0.16 \mathrm{~mol} \mathrm{dm}^{-3}\right)$ with modified experimental design and titration assembly given elsewhere [15].

The effects of dielectric constant, variations in liquid junction potential, asymmetry potential, dissolved carbon dioxide, sodium ion error, and activity coefficient on the response of the electrode were explained by correction factor estimated by SCPHD program [32, 33]. For a reliable determination of stability constants corresponding to mixed ligand model complexes, pooled data refinement of all the experimental trial using MINIQUAD75 computer program was chosen. The results of the free acid correction factor, values of $\mathrm{Kw}$, protonation constants of the ligands [22] and binary M-L complex constants [26] were fixed and used as initial imputes in the analysis of the mixed ligand complexes using MINIQUAD75 program [33-34] with inbuilt statistical parameters of chemical model refinement tools.

Typical mixed ligand metal complexes were published by different researchers in the form of Orn-M(II)-ligand and phen-M(II)-ligand with brief account of the systems [35-38], and the present study is presented for comparison in Table 1. 
Table 1

Comparison of the stability constants values of L-M-X complexes with previously reported literature values refined by MINIQUAD75 program, where $L, M$ and $X$ stand for metal ions, $1^{\circ}$ and $2^{\circ}$ ligands respectively.

\begin{tabular}{|c|c|c|c|c|c|c|c|c|}
\hline \multirow[t]{2}{*}{ System } & \multicolumn{4}{|c|}{$\log \beta_{m l x h}$} & \multirow[t]{2}{*}{$\left(T^{0} \mathrm{C} / \mu\right)$} & \multirow[t]{2}{*}{ Instrumental method } & \multirow{2}{*}{$\begin{array}{l}\text { Solvents/ } \\
\text { Media }\end{array}$} & \multirow[t]{2}{*}{ Ref } \\
\hline & MLX & $\mathrm{MLXH}$ & $\mathrm{ML}_{2} \mathrm{X}$ & $\mathrm{MLX}_{2} \mathrm{H}$ & & & & \\
\hline (Asp)Cu(II)(Orn) & 15.29 & - & 14.60 & - & $298 / 0.1 \mathrm{M}$ & $\mathrm{pH}$ metry & Aqueous & [35] \\
\hline (En)Co(II)(Orn) & 11.85 & 19.30 & 14.60 & - & $303 / 0.16 \mathrm{M}$ & pH metry & Aqueous & [36] \\
\hline (En)Ni(II)(Orn) & 21.10 & 15.08 & 19.62 & - & $303 / 0.16 \mathrm{M}$ & $\mathrm{pH}$ metry & Aqueous & [36] \\
\hline (En)Cu(II)(Orn) & 25.55 & 28.14 & 30.69 & - & $303 / 0.16 \mathrm{M}$ & $\mathrm{pH}$ metry & Aqueous & [36] \\
\hline GluCu(II)Phen & 17.91 & 27.04 & - & - & 298/0.1 M & $\mathrm{pH}$ metry & Aqueous & [37] \\
\hline PydiCAln(III)Phen & 17.36 & 26.93 & - & - & $298 / 0.1 \mathrm{M}$ & pH metry & Aqueous & [38] \\
\hline \multirow[t]{3}{*}{ OrnCo(II)Phen } & 14.45 & 21.12 & 19.21 & 28.07 & $298 / 0.16 \mathrm{M}$ & pH metry & Aqueous & This study \\
\hline & 12.84 & 19.88 & 17.89 & 27.18 & $298 / 0.16 \mathrm{M}$ & $\mathrm{pH}$ metry & TBAB & This study \\
\hline & 12.74 & 19.68 & 17.39 & 27.03 & $298 / 0.16 \mathrm{M}$ & pH metry & PEG-400 & This study \\
\hline \multirow[t]{3}{*}{ OrnNi(II)Phen } & 27.12 & 29.45 & 28.37 & 31.63 & $298 / 0.16 \mathrm{M}$ & $\mathrm{pH}$ metry & Aqueous & This study \\
\hline & 25.59 & 27.49 & 26.21 & 30.13 & $298 / 0.16 \mathrm{M}$ & $\mathrm{pH}$ metry & TBAB & This study \\
\hline & 25.27 & 27.10 & 26.12 & 28.66 & $298 / 0.16 \mathrm{M}$ & pH metry & PEG-400 & This study \\
\hline \multirow[t]{3}{*}{ OrnCu(II)Phen } & 28.80 & 34.78 & 30.32 & 44.65 & $298 / 0.16 \mathrm{M}$ & pH metry & Aqueous & This study \\
\hline & 26.83 & 29.84 & 27.58 & 37.78 & $298 / 0.16 \mathrm{M}$ & pH metry & TBAB & This study \\
\hline & 25.36 & 29.74 & 27.73 & 37.68 & $298 / 0.16 \mathrm{M}$ & $\mathrm{pH}$ metry & PEG-400 & This study \\
\hline
\end{tabular}

\section{Results And Discussion}

\subsection{Chemical models of mixed ligand complexes}

Reliable and best representative models for the experimental data were obtained by increasing the number of species to be refined, satisfying statistical refinement parameters. This indicates that the final model appropriately fits with the experimental data. The plausible chemical models for Orn-M(II)-Phen mixed ligand systems in aqueous TBAB or PEG-400 medium for $\mathrm{Co}(\mathrm{II}), \mathrm{Ni}(\mathrm{II})$ and $\mathrm{Cu}(\mathrm{II})$ along with the magnitude of the corresponding stability constants are given (Tables 2 and 3 ).

The species successfully converged and finally refined in the active $\mathrm{pH}$ ranges were $\mathrm{MLX}, \mathrm{MLXH}, \mathrm{MLX}_{2} \mathrm{H}$ and $\mathrm{ML}_{2} \mathrm{X}$ for all $\mathrm{Co}(\mathrm{II}), \mathrm{Ni}(\mathrm{II})$ and $\mathrm{Cu}(\mathrm{II})$ in PEG-400- and TBAB-water mixture. The results of refinement under the parameters of the best-fit models are presented in Tables 2 and 3. The best fit models were found to be chemically consistent with better statistical fits to the electrometric titration data without showing systematic trends in the overall magnitude of the residuals. The standard deviations in $\log \beta$ values were also very low and $U_{\text {corr }}$ were very small, indicating the precision of the parameters; the good agreement of the models converged to the titration data and consistency of the model, respectively [39]. The slight left or right distribution of errors has been clearly shown by the magnitude of the skewness close to zero and hence a least squares method may be applied to the generated data. The values of kurtosis were virtually observed to be greater than 3 for which the residuals form part of leptokurtic pattern of distribution errors $[8,40]$.

The representativeness of the chemical models and its sufficiency has been indicated by the very low values of crystallographic $\mathrm{R}$ factor given in Tables 2 and 3. This enabled to consider additional species in the proposed and converged models. The gamma ( $\mathrm{Y}$ ) distribution, $\chi^{2}$, measures the probability of residuals to form part of standard normal distribution curve [8, 
Table 2

Best fit chemical models of Orn-M-Phen complexes in PEG- 400-water media. Temperature $=298 \mathrm{~K}$, lonic strength $=0.16$ mol L-1 . M stands for $\mathrm{Co}(\mathrm{II}), \mathrm{Ni}(\mathrm{II})$ or $\mathrm{Cu}(\mathrm{II})$.

\begin{tabular}{|c|c|c|c|c|c|c|c|c|c|c|}
\hline \multirow{2}{*}{$\begin{array}{l}\% \\
v / v \\
\text { PEG- } \\
400\end{array}$} & \multicolumn{3}{|c|}{$\log \beta_{\mathrm{mlxh}}(\mathrm{SD})$} & \multicolumn{2}{|l|}{ NP } & \multirow{2}{*}{$\begin{array}{l}\mathrm{U}_{\text {corr }} \\
\times 10^{8}\end{array}$} & \multirow[t]{2}{*}{$x^{2}$} & \multirow[t]{2}{*}{ Skewness } & \multirow[t]{2}{*}{ Kurtosis } & \multirow{2}{*}{$\begin{array}{l}\text { R- } \\
\text { factor }\end{array}$} \\
\hline & MLX & MLXH & $\mathrm{ML}_{2} \mathrm{X}$ & $M L X_{2} H$ & & & & & & \\
\hline \multicolumn{11}{|c|}{ Co(II) (pH 1.67-10.5) } \\
\hline 0.0 & $14.45(23)$ & 21.12(19) & $19.21(21)$ & $28.07(16)$ & 159 & 1.96 & 25.08 & 1.34 & 6.23 & 0.0110 \\
\hline 0.5 & $13.13(13)$ & 20.85(12) & $18.86(15)$ & $27.28(18)$ & 148 & 1.35 & 63.54 & -0.06 & 9.49 & 0.0016 \\
\hline 1.0 & $13.10(11)$ & 20.01(12) & $18.43(11)$ & $26.65(12)$ & 116 & 2.34 & 9.25 & 0.30 & 6.25 & 0.0012 \\
\hline 1.5 & $12.84(14)$ & 19.88(15) & $17.89(16)$ & 27.18(10) & 99 & 2.04 & 6.30 & -0.96 & 6.30 & 0.0036 \\
\hline 2.0 & $12.69(10)$ & 19.54(11) & $17.31(10)$ & $26.23(08)$ & 78 & 1.13 & 19.14 & -0.75 & 4.48 & 0.0101 \\
\hline 2.5 & $12.43(8)$ & 19.28(10) & $17.14(12)$ & $26.03(10)$ & 57 & 1.98 & 7.04 & -0.58 & 5.38 & 0.0017 \\
\hline \multicolumn{11}{|c|}{$\mathrm{Ni}(\mathrm{II})(\mathrm{pH} 1.6-6.5)$} \\
\hline 0.0 & 27.12(38) & 29.45(34) & $28.37(42)$ & $31.63(37)$ & 240 & 3.85 & 72.82 & -0.33 & 3.91 & 0.0028 \\
\hline 0.5 & 27.41(10) & 29.14(11) & 27.93(12) & $30.28(12)$ & 119 & 6.16 & 102.62 & -0.44 & 2.70 & 0.0016 \\
\hline 1.0 & 26.33(18) & $28.52(27)$ & $27.19(28)$ & $29.98(26)$ & 71 & 1.49 & 44.18 & -0.60 & 5.42 & 0.0025 \\
\hline 1.5 & $25.59(23)$ & $27.49(24)$ & $26.21(32)$ & $30.13(52)$ & 35 & 0.18 & 25.75 & -0.60 & 4.37 & 0.0023 \\
\hline 2.0 & $25.12(22)$ & $27.64(21)$ & $26.23(21)$ & 28.84(41) & 53 & 0.24 & 4.34 & -0.03 & 4.57 & 0.0032 \\
\hline 2.5 & $25.00(17)$ & 26.41(18) & $26.08(15)$ & $28.53(12)$ & 61 & 1.35 & 2.50 & -0.49 & 3.42 & 0.0069 \\
\hline \multicolumn{11}{|c|}{$\mathrm{Cu}(\mathrm{II})(\mathrm{pH} 1.6-10.0)$} \\
\hline 0.0 & $28.80(10)$ & 34.78(13) & $30.32(12)$ & $44.65(12)$ & 134 & 7.55 & 9.36 & -0.82 & 5.04 & 0.0014 \\
\hline 0.5 & $28.07(7)$ & $33.26(14)$ & $28.38(13)$ & $42.28(32)$ & 131 & 6.76 & 14.05 & -0.45 & 2.54 & 0.0017 \\
\hline 1.0 & $27.18(6)$ & $30.93(23)$ & $27.43(16)$ & $40.89(16)$ & 98 & 1.91 & 3.80 & -0.81 & 6.50 & 0.0082 \\
\hline 1.5 & 26.83(8) & 29.84(34) & 27.58(33) & $37.78(35)$ & 74 & 1.05 & 5.38 & -1.00 & 7.02 & 0.0091 \\
\hline 2.0 & 24.97(6) & $27.37(24)$ & $26.63(10)$ & 33.33(12) & 56 & 0.73 & 8.84 & -0.05 & 5.21 & 0.0093 \\
\hline 2.5 & $24.46(9)$ & 26.78(10) & $25.49(11)$ & $23.49(14)$ & 91 & 0.83 & 3.43 & -0.83 & 2.96 & 0.0042 \\
\hline
\end{tabular}


Table 3

Best fit chemical models of Orn-M-Phen complexes in TBAB-water media. Temperature $=298 \mathrm{~K}$, lonic strength $=0.16 \mathrm{~mol} \mathrm{~L}-1$. $\mathrm{M}$ stands for $\mathrm{Co}(\mathrm{II}), \mathrm{Ni}(\mathrm{II})$ or $\mathrm{Cu}(\mathrm{II})$.

\begin{tabular}{|c|c|c|c|c|c|c|c|c|c|c|}
\hline \multirow{2}{*}{$\begin{array}{l}\% \mathrm{w} / \mathrm{v} \\
\text { TBAB }\end{array}$} & \multicolumn{4}{|c|}{$\log \beta_{\mathrm{mlxh}}(\mathrm{SD})$} & \multirow[t]{2}{*}{ NP } & \multirow{2}{*}{$\begin{array}{l}U_{\text {corr }} \\
\times 10^{8}\end{array}$} & \multirow[t]{2}{*}{$x^{2}$} & \multirow[t]{2}{*}{ Skewness } & \multirow[t]{2}{*}{ Kurtosis } & \multirow[t]{2}{*}{$R$-factor } \\
\hline & MLX & MLXH & $\mathrm{ML}_{2} \mathrm{X}$ & $\mathrm{MLX}_{2} \mathrm{H}$ & & & & & & \\
\hline \multicolumn{11}{|c|}{$\mathrm{Co}(\mathrm{II})(\mathrm{pH} 2.0-10.0)$} \\
\hline 0.0 & $14.45(23)$ & 21.12(19) & 19.21(21) & $28.07(16)$ & 159 & 1.96 & 25.08 & 1.34 & 6.23 & 0.0110 \\
\hline 0.5 & $13.10(04)$ & $20.25(07)$ & $18.36(16)$ & 27.00(19) & 143 & 2.25 & 51.71 & -0.12 & 3.18 & 0.0014 \\
\hline 1.0 & $12.95(12)$ & $19.92(10)$ & 17.91(14) & $26.25(13)$ & 104 & 0.78 & 6.36 & -0.42 & 5.45 & 0.0012 \\
\hline 1.5 & $12.74(14)$ & $19.68(12)$ & $17.39(18)$ & $27.03(21)$ & 90 & 1.52 & 8.93 & 0.38 & 4.00 & 0.0044 \\
\hline 2.0 & $12.59(19)$ & $18.76(17)$ & $17.15(15)$ & $26.12(16)$ & 81 & 0.89 & 12.21 & -0.72 & 8.43 & 0.0059 \\
\hline 2.5 & $11.48(38)$ & $18.43(20)$ & $16.84(32)$ & $25.71(41)$ & 52 & 1.26 & 9.12 & -0.76 & 9.98 & 0.0019 \\
\hline \multicolumn{11}{|c|}{$\mathrm{Ni}(\mathrm{II})(\mathrm{pH} 2.0-6.0)$} \\
\hline 0.0 & $27.12(38)$ & $29.45(34)$ & $28.37(42)$ & $31.63(37)$ & 240 & 3.85 & 72.82 & -0.33 & 3.91 & 0.0028 \\
\hline 0.5 & 27.11(10) & 29.05(13) & 27.54(18) & 29.93(23) & 98 & 2.23 & 53.62 & -0.26 & 4.36 & 0.0021 \\
\hline 1.0 & 26.22(17) & 28.32(27) & 27.03(20) & 29.52(26) & 59 & 1.55 & 26.86 & -0.82 & 6.89 & 0.0012 \\
\hline 1.5 & $25.27(23)$ & 27.10(19) & $26.12(32)$ & $28.66(55)$ & 46 & 0.62 & 14.8 & -0.03 & 4.59 & 0.0053 \\
\hline 2.0 & $24.94(25)$ & $27.14(24)$ & $25.79(21)$ & $27.94(41)$ & 53 & 0.37 & 4.5 & -0.03 & 4.57 & 0.0039 \\
\hline 2.5 & 24.83(14) & $25.87(18)$ & $25.15(15)$ & 27.48(12) & 48 & 1.03 & 7.80 & -0.56 & 13.2 & 0.0090 \\
\hline \multicolumn{11}{|c|}{$\mathrm{Cu}(\mathrm{II})(\mathrm{pH} 1.4-10.0)$} \\
\hline 0.0 & $28.80(10)$ & $34.78(13)$ & $30.32(12)$ & $44.65(12)$ & 134 & 7.55 & 9.36 & -0.82 & 5.04 & 0.0014 \\
\hline 0.5 & 27.21(07) & $33.12(14)$ & 29.38(11) & 41.88(19) & 131 & 4.60 & 12.0 & -0.54 & 5.34 & 0.0021 \\
\hline 1.0 & $26.32(09)$ & $30.93(21)$ & $28.29(16)$ & $39.88(18)$ & 87 & 1.18 & 3.60 & 0.65 & 4.57 & 0.0079 \\
\hline 1.5 & $25.36(08)$ & $29.74(12)$ & $27.73(30)$ & $37.68(26)$ & 70 & 0.98 & 7.46 & -0.12 & 7.0 & 0.0093 \\
\hline 2.0 & $24.57(05)$ & $28.37(14)$ & $26.77(15)$ & 35.33(12) & 63 & 0.76 & 5.64 & -1.03 & 2.73 & 0.0078 \\
\hline 2.5 & 23.48(07) & 27.78(09) & $25.79(10)$ & $23.29(11)$ & 76 & 0.94 & 4.35 & -0.73 & 6.58 & 0.0033 \\
\hline
\end{tabular}

\subsection{Validation of the chemical models and interpretation of systematic errors}

The sufficiency and quality of the best fit chemical model have been evaluated through the introduction of pessimistic errors in the concentrations ( $\pm 2 \%$ and $\pm 5 \%$ ) of acid, alkali, ligand molecules and metal ions of interest. The validation was made in order to test the reliability and accuracy of data acquisition under varied experimental conditions. The results of refinements for the data subjected to pessimistic errors were found to show high standard deviation in $\log \beta$ values, significant deviation in the magnitude of the stability constants and rejection of some of the proposed models by MINIQUAD75 algorithm. The effects of errors were more profoundly observed in alkali and acids than ligands and the metal ions as their concentration changed systematically. This shows the sufficiency of the models and accuracy of the method. The results of typical data in 1.5 \% PEG-400 and TBAB are given in Table 4. 
Table 4

Effect of errors in concentrations of influential parameters on the stability constants of Orn-Ni(II)-Phen complexes in $1.5 \%$ (v/v) surfactant-water mixtures.

\begin{tabular}{|c|c|c|c|c|c|c|c|c|c|}
\hline \multirow[t]{3}{*}{ Ingredient } & \multirow[t]{3}{*}{$\%$ of error } & \multicolumn{8}{|c|}{$\log \beta_{\mathrm{mlxh}}(S D)$} \\
\hline & & \multicolumn{4}{|c|}{ Aqua-PEG-400 } & \multicolumn{4}{|c|}{ Aqua-TBAB } \\
\hline & & MLX & MLXH & $\mathrm{ML}_{2} \mathrm{X}$ & $\mathrm{MLX}_{2} \mathrm{H}$ & MLX & MLXH & $\mathrm{ML}_{2} \mathrm{X}$ & $\mathrm{MLX}_{2} \mathrm{H}$ \\
\hline & 0 & $25.27(23)$ & $27.10(19)$ & $26.12(15)$ & $30.33(12)$ & $25.36(6)$ & $29.74(12)$ & $27.73(10)$ & $37.68(12)$ \\
\hline & -5 & Rejected & Rejected & 28.33(8) & $35.15(12)$ & Rejected & Rejected & 29.39(08) & Rejected \\
\hline \multirow[t]{4}{*}{ Alkali } & -2 & Rejected & $28.54(23)$ & 28.68(29) & Rejected & Rejected & $28.54(23)$ & $28.72(29)$ & Rejected \\
\hline & +2 & $26.43(21)$ & $27.75(25)$ & $24.98(53)$ & $33.62(43)$ & $26.35(21)$ & $27.75(25)$ & $26.26(53)$ & $35.57(44)$ \\
\hline & +5 & $25.12(27)$ & $26.78(28)$ & $25.00(53)$ & $30.81(49)$ & $25.19(27)$ & $26.78(28)$ & $24.23(53)$ & $30.45(49)$ \\
\hline & -5 & $24.40(20)$ & $26.35(21)$ & 27.11(26) & $32.78(43)$ & $24.42(15)$ & $28.35(21)$ & $27.11(26)$ & $38.92(18)$ \\
\hline \multirow[t]{4}{*}{ Acid } & -2 & $25.19(18)$ & $26.06(20)$ & $26.53(48)$ & $29.56(65)$ & $25.23(28)$ & $29.06(20)$ & $26.53(48)$ & $29.76(28)$ \\
\hline & +2 & Rejected & $25.19(21)$ & 27.39(32) & 28.93(34) & Rejected & $26.19(21)$ & Rejected & $30.93(16)$ \\
\hline & +5 & Rejected & Rejected & $26.23(23)$ & $28.56(18)$ & Rejected & Rejected & $26.23(23)$ & $29.55(25)$ \\
\hline & -5 & $26.10(7)$ & $27.40(8)$ & $26.38(6)$ & $31.03(10)$ & $26.23(7)$ & $29.40(9)$ & $26.38(6)$ & $38.3(11)$ \\
\hline \multirow[t]{4}{*}{$\operatorname{Orn}(\mathrm{L})$} & -2 & $25.89(7)$ & 27.42(8) & $26.52(16)$ & $30.36(9)$ & $26.67(10)$ & $29.50(9)$ & $26.45(18)$ & $37.26(8)$ \\
\hline & +2 & 25.71(7) & $27.35(7)$ & 26.31(9) & $30.53(17)$ & $25.56(17)$ & $29.42(6)$ & 26.31(9) & $36.64(9)$ \\
\hline & +5 & 25.73(8) & $27.29(7)$ & $26.55(21)$ & $30.27(12)$ & $25.32(11)$ & 29.33(7) & $26.15(12)$ & $36.48(11)$ \\
\hline & -5 & $27.05(9)$ & $27.80(8)$ & $26.83(21)$ & $30.53(8)$ & $26.16(19)$ & $29.71(12)$ & $26.44(21)$ & $37.89(13)$ \\
\hline \multirow[t]{4}{*}{ Phen $(X)$} & -2 & $26.58(8)$ & $27.65(6)$ & $26.45(18)$ & $30.18(7)$ & $25.61(10)$ & 29.12(9) & $26.57(15)$ & $37.33(10)$ \\
\hline & +2 & $25.81(7)$ & $27.52(5)$ & $26.13(10)$ & $30.37(7)$ & $25.49(8)$ & $29.15(6)$ & $26.24(7)$ & $36.30(08)$ \\
\hline & +5 & $25.75(7)$ & $27.41(6)$ & $26.15(12)$ & $29.94(10)$ & $25.36(6)$ & $29.74(12)$ & $27.73(10)$ & $37.68(12)$ \\
\hline & -5 & $25.98(6)$ & 27.46(8) & $26.40(10)$ & $30.27(7)$ & Rejected & $28.54(23)$ & $28.72(29)$ & Rejected \\
\hline \multirow[t]{3}{*}{ Metal } & -2 & $25.77(5)$ & 27.42(8) & $26.52(14)$ & $30.36(10)$ & $26.35(21)$ & $27.75(25)$ & $26.26(53)$ & $35.57(44)$ \\
\hline & +2 & $25.66(5)$ & 27.35(9) & $26.24(12)$ & $30.47(9)$ & $25.19(27)$ & $26.78(28)$ & $24.23(53)$ & $30.45(49)$ \\
\hline & +5 & $25.43(6)$ & $27.31(7)$ & $26.25(21)$ & $30.45(8)$ & $25.12(21)$ & $26.52(23)$ & $24.02(41)$ & $30.32(35)$ \\
\hline
\end{tabular}

\subsection{Effect of surfactant}

The additions of PEG-400 and TBAB lowered the dielectric constant $[6,41,42]$ of the aqueous medium, thereby decreasing log $\beta$ values. Moreover, PEG-400 (neutral) and TBAB (cationic) surfactants have destabilizing effects on the positively charged complexes formed due to electrostatic repulsive effects which synergizes with the lower dielectric constants causing $\log \beta$ values to decrease. Thus, in the present study, $\log \beta$ values of the mixed ligand system were found to be linearly decreasing with increasing percentage of PEG-400 or TBAB (Fig. 1), which causes destabilization of the complexes with net predominant effect of electrostatic factors.

\subsection{Prediction of extra stability of the mixed ligand complexes}

The relative stabilities of mixed ligand complexes, compared to their binary counterparts, can be predicted from disproportionation equilibria [13-15; 34-35; 43], and the change in the Log values of stability constants ( $\Delta \log K)$ [8]. The disproportionation constant (log X) [44-47] which corresponds to equilibrium 3 and the change in the Log values of stability constants $(\Delta \log K)[8]$ of mixed ligand complexes and their parent binary complexes are given by Eqs. 2 and 3, respectively. The two different ligands have mutually the same degree of influence in the formation of mixed ligand complex $[14,15,34,43]$. 


\begin{tabular}{|c|c|}
\hline $\mathrm{ML}_{2}+\mathrm{MX}_{2} \rightleftharpoons 2 \mathrm{MLX}$ & (1) \\
\hline $\log \mathrm{X}=2 \log \mathrm{K}_{\mathrm{MLX}}^{\mathrm{M}}-\log \mathrm{K}_{\mathrm{ML}_{2}}^{\mathrm{M}}-\log \mathrm{K}_{\mathrm{MX}_{2}}^{\mathrm{M}}$ & (2) \\
\hline$\Delta \log K=\log K_{M L}^{M}-\log K_{M L}^{M}-\log K_{M X}^{M} \mathrm{M}(\mathrm{I}) \ldots$ & (3) \\
\hline
\end{tabular}

The formation of a mixed ligand complex of two different ligands, $M L X$, is statistically more favored than the formation of the parent $M L_{2}$ and $\mathrm{MX}_{2}$ binary complexes when equal concentrations of $\mathrm{M}, \mathrm{L}$ and $\mathrm{X}$ are available in solutions [12]. $A d d i t i o n a l l y, M L_{2}(25 \%)$ and $M X_{2}$ (25\%) complexes can readily form mixed ligand complexes, $2 \mathrm{MLX}(50 \%)$, and the value of log X was reported to be 0.6 [17, $18 ; 21,47,48]$.

The value of $\Delta \log \mathrm{K}$ should be negative when either of the ligands coordinates with the free metal ion in comparison to the simple complexes in binary system, where the log value of first stepwise stability constant $\mathrm{K}_{1}$ is always greater than the log value of second stepwise stability constant $\mathrm{K}_{2}$. The change in log values of the mixed ligand constant ( $\left.\Delta \log \mathrm{K}\right)$ is usually positive. Thus, the $\Delta$ log $\mathrm{K}$ could be taken as better measure of the tendency towards the formation of mixed ligand complexes than severely criticized log values of overall stability constants $[13,43]$.

Based on the electrostatic theory of binary complex formation and statistical arguments, the additional site of coordination of given multivalent hydrated central metal ion could easily be available for the first ligand than for the second, probably due to steric hindrance. Hence, the usual order of stability> applies. This suggests that $\Delta \log \mathrm{K}$ should be negative although several exceptions [46] have been found. In the case of bidentate ligands, there are twelve edges of normal octahedron available for first coordinating ligand leaving only five for the second entering ligand and accordingly, (-5/12 -0.4). The statistical values of $\Delta \log \mathrm{K}_{\mathrm{oh}}, \Delta \log \mathrm{K}_{\mathrm{pl}}$, and $\Delta$ log $\mathrm{K}_{\mathrm{disoh}}$ for bidentate $\mathrm{L}$ and $X$ are $-0.4,-0.6$ and between -0.9 and -0.3 for octahedral, square planar and distorted octahedral complexes, respectively. Whenever the experimental values of $\Delta \log \mathrm{K}$ exceed the critical values, the mixed ligand complex is supposed to be formed due to interaction of $\mathrm{ML}$ with $\mathrm{X}$ or MX with L. Some of $\Delta \log \mathrm{K}$ values of mixed ligand complexes reported containing bipyridyl as the primary ligand are positive [13, 43] for O-donor (malonic acid, pyrocatechol, etc.), negative for $\mathrm{N}$-donors (ethylenediamine) and intermediate or negative [40] for amino acids with $\mathrm{N}$ and $\mathrm{O}$ binding sites.

$\Delta \log \mathrm{K}_{\mathrm{MLXH}}=\log \beta_{\mathrm{MLXH}}-\log \beta_{\mathrm{MLH}}-\log \beta_{\mathrm{MX}}$

In the present study, it was impossible to calculate the values of $\Delta$ log $\mathrm{K}$ for Ni(II), Co(II) except for MLX ${ }_{2} \mathrm{H}$ model (1.57-3.14 in PEG-400, 3.39-5.51 in TBAB) and some models of $\mathrm{Cu}(\mathrm{II})$ due to the absence of some of the binary chemical models [26]. For the mixed ligand complexes of $\mathrm{Cu}(\mathrm{II})$, the values of $\Delta \log \mathrm{K}$ were found to range from -8.19 to 6.96 in PEG-400 and - 8.7 to 10.18 in TBAB-water mixtures, respectively. For all the metal complexes, the values of $\log X$ and $\Delta \log \mathrm{K}$ were observed to be higher than the statistical values (0.6) and (-0.4), respectively, suggesting extra stability of the mixed ligand complexes.

In the Orn-M(II)-Phen system, the central metal ion forms octahedral complexes, where $\mathrm{M}$ stands for $\mathrm{Co}(\mathrm{II}), \mathrm{Ni}(\mathrm{II})$ and $\mathrm{Cu}(\mathrm{II})$. For all the $\mathrm{M}-\mathrm{L}$ systems (Table 6), the $\Delta \log \mathrm{K}$ values were found to be higher than statistical grounds $(-0.4)$, indicating the extra stabilities of the mixed ligand complexes compared to their parent binary model complexes. The interactions of the system outside the coordination sphere like the formation of $\mathrm{H}$-bonding between the coordinated ligands, chelated ring effect, charge neutralization, stacking interactions and electrostatic interactions between non-coordinated charge groups of the ligands could be listed as the plausible reasons for the extra stabilities of the mixed ligand complexes [11, 49].

The values of $\Delta \log \mathrm{K}$ and $\log \mathrm{X}$ are calculated from the magnitude of stability constants of binary and mixed ligand models using the selected equations given in Table 5. The values of $\Delta \log \mathrm{K}$ for the formation of $\mathrm{MLX}, \mathrm{MLXH}, \mathrm{ML}_{2} \mathrm{X}$ and $\mathrm{MLX}_{2} \mathrm{H}$ model species for Cu(II) are very near to or on positive sides of the statistically allowed values, indicating the tendency of the formation of $M L X, M L X H, M L{ }_{2}$ and $\mathrm{MLX}_{2} \mathrm{H}$ complex species with different relative stabilities. With respect to mixed ligand complexes of Co(II), the values of $\Delta$ log $\mathrm{K}$ of $\mathrm{MLX} \mathrm{H}_{2}$ complex was also found to be on the positive side of the statistically expected values, indicating the preference of mixed ligand complex formation due to favoured entropy change, arisen mainly from charge neutralization with release of solvent molecules. However, the negative $\Delta \log \mathrm{K}$ values do not preclude the tendency towards the formation of mixed ligand species.

When the charges of the two different ligands are not equal, electrostatic factor also contributes for the formulation of log $X$. The log $X$ values for all Orn-M(II)-Phen system were observed to be higher than the known table value of the disproportion constant (usually 0.6) 
which reveals the extra stability of the mixed ligand complex (Table 6). It also indicates that statistical and electrostatic factors are applied favourably for the formation of mixed ligand complexes.

Table 5

Selected equations used to calculate $\Delta \log \mathrm{K}$ and $\log \mathrm{X}$ values from the magnitude of corresponding overall stability constants.

\begin{tabular}{|llll|}
\hline$\Delta \log \mathrm{K}$ & & & \\
\hline$\Delta \log \mathrm{K}_{1110}$ & $=\log \beta_{1110}$ & $-\log \beta_{1100}$ & $-\log \beta_{1010}$ \\
\hline$\Delta \log \mathrm{K}_{1210}$ & $=\log \beta_{1210}$ & $-\log \beta_{1200}$ & $-\log \beta_{1010}$ \\
\hline$\Delta \log \mathrm{K}_{1121}$ & $=\log \beta_{1121}$ & $-\log \beta_{1101}$ & $-\log \beta_{1020}$ \\
\hline & $=\log \beta_{1121}$ & $-\log \beta_{1100}$ & $-\log \beta_{1021}$ \\
\hline$\Delta \log \mathrm{K}_{1111}$ & $=\log \beta_{1111}$ & $-\log \beta_{1101}$ & $-\log \beta_{1010}$ \\
\hline $\log \mathrm{X}$ & & & \\
\hline
\end{tabular}

Table 6

$\triangle \log \mathrm{K}$ and $\log \mathrm{X}$ values of mixed ligand complexes of $\mathrm{Co}(\mathrm{II}), \mathrm{Ni}(\mathrm{II})$ and $\mathrm{Cu}(\mathrm{II})-\mathrm{Orn}$ and Phen in PEG-400-

and TBAB-water mixtures.

\begin{tabular}{|llll|}
\hline $\log X_{1110}$ & $=2 \log \beta_{1110}$ & $-\log \beta_{1200}$ & $-\log \beta_{1020}$ \\
\hline $\log X_{1210}$ & $=2 \log \beta_{1210}$ & $-\log \beta_{1400}$ & $-\log \beta_{1020}$ \\
$\log X_{1121}$ & $=2 \log \beta_{1121}$ & $-\log \beta_{1201}$ & $-\log \beta_{1041}$ \\
& $=2 \log \beta_{1121}$ & $-\log \beta_{1200}$ & $-\log \beta_{1042}$ \\
$\log X_{1111}$ & $=2 \log \beta_{1111}$ & $-\log \beta_{1202}$ & $-\log \beta_{1020}$ \\
\hline
\end{tabular}




\begin{tabular}{|c|c|c|c|c|c|}
\hline & \multicolumn{4}{|c|}{$\Delta \log \mathrm{K}$} & \multirow{2}{*}{$\begin{array}{l}\log X \\
1110\end{array}$} \\
\hline & 1110 & 1111 & 1210 & 1121 & \\
\hline \multicolumn{6}{|c|}{ \% v/v PEG-400 } \\
\hline \multicolumn{6}{|c|}{$\mathrm{Co}(\mathrm{II})$} \\
\hline 0.0 & - & - & - & 1.86 & -1.39 \\
\hline 0.5 & - & - & - & 1.57 & -2.53 \\
\hline 1.0 & - & - & - & 1.80 & -2.42 \\
\hline 1.5 & - & - & - & 3.14 & -1.63 \\
\hline 2.0 & - & - & - & 2.79 & -1.10 \\
\hline 2.5 & - & - & - & 2.97 & -0.85 \\
\hline \multicolumn{6}{|c|}{$\mathrm{Ni}(\mathrm{II})$} \\
\hline 0.0 & - & - & - & - & 26.38 \\
\hline 0.5 & - & - & - & - & 28.20 \\
\hline 1.0 & - & - & - & - & 27.38 \\
\hline 1.5 & - & - & - & - & 26.21 \\
\hline 2.0 & - & - & - & - & 25.30 \\
\hline 2.5 & - & - & - & - & 25.92 \\
\hline \multicolumn{6}{|c|}{$\mathrm{Cu}(\mathrm{II})$} \\
\hline 0.0 & 3.51 & 6.96 & -8.19 & 10.11 & 12.37 \\
\hline 0.5 & 4.03 & 6.36 & -6.72 & 8.57 & 14.23 \\
\hline 1.0 & 4.07 & 4.53 & -5.96 & 8.34 & 14.82 \\
\hline 1.5 & 3.63 & 4.66 & -7.02 & 6.41 & 12.87 \\
\hline 2.0 & 1.64 & 2.31 & -7.49 & 1.90 & 09.45 \\
\hline 2.5 & 2.25 & 1.11 & -6.79 & -8.52 & 10.30 \\
\hline \multicolumn{6}{|c|}{$\%$ w/v TBAB } \\
\hline \multicolumn{6}{|c|}{$\mathrm{Co}(\mathrm{II})$} \\
\hline 0.0 & - & - & - & 3.39 & -1.39 \\
\hline 0.5 & - & - & - & 4.28 & -2.01 \\
\hline 1.0 & - & - & - & 4.96 & -0.95 \\
\hline 1.5 & - & - & - & 5.03 & -1.23 \\
\hline 2.0 & - & - & - & 5.00 & 0.06 \\
\hline 2.5 & - & - & - & 5.51 & -0.04 \\
\hline \multicolumn{6}{|c|}{$\mathrm{Cu}(\mathrm{II})$} \\
\hline 0.0 & - & - & - & 10.18 & 12.44 \\
\hline 0.5 & - & - & - & 9.49 & 15.15 \\
\hline 1.0 & - & - & - & 7.73 & 14.21 \\
\hline 1.5 & - & - & - & 6.49 & 12.95 \\
\hline 2.0 & - & - & - & 1.80 & 09.35 \\
\hline
\end{tabular}




\begin{tabular}{|llllll|}
\hline \multicolumn{3}{|c}{$\Delta \log \mathrm{K}$} & & & $\log \mathrm{X}$ \\
\hline & $\mathbf{1 1 1 0}$ & $\mathbf{1 1 1 1}$ & $\mathbf{1 2 1 0}$ & $\mathbf{1 1 2 1}$ & $\mathbf{1 1 1 0}$ \\
\hline 2.5 & - & - & - & -8.7 & 10.12 \\
\hline
\end{tabular}

\subsection{Chemical Speciation and species distribution plots}

The species distribution diagrams for the Orn-M(II)-Phen system plotted from SIM run best fit model data are presented in Figs. 2 and 3 . In the plots, both binary, with relatively low percentage composition [26], and mixed ligand complexes, with higher percentage compositions, co-exist in the active $\mathrm{pH}$ regions due to inbuilt provision of MINIQUAD75 program. This indicates that mixed ligand complexes have extra stabilities compared to their parent binary complexes of the same metal ion under exactly the same experimental conditions. The plausible chemical models converged for mixed ligand complexes of $\operatorname{Orn}(\mathrm{L})$ and Phen $(\mathrm{X})$ in PEG-400- and TBAB-water mixtures are MLXH, $\mathrm{MLX}, \mathrm{MLX}_{2} \mathrm{H}$ and $\mathrm{ML}_{2} \mathrm{X}$ for all the metals. $\mathrm{MLXH}$ and $\mathrm{MLX}{ }_{2} \mathrm{H}$ model species exist at lower $\mathrm{pH}$ while $\mathrm{MLX}$ and $\mathrm{ML}_{2} \mathrm{X}$ were found at higher $\mathrm{pH}$ (cf. Figures 2 and 3).

As shown in Equilibrium (4), MLXH is formed by direct combination of the free metal ion, $\mathrm{M}(\mathrm{II})$, with $\mathrm{LH}$ and $\mathrm{XH}_{2}$ forms of primary and secondary ligands in the $\mathrm{pH}$ ranges of 1.5-11.0; 1.5-7.0 and 1.5-11.0 with max extent of formation, resulting in the formation of complexes with different amounts, e.g. $60-80 \%$ for $\mathrm{Co}(\mathrm{II}) ; 35-80 \%$ for $\mathrm{Ni}(\mathrm{II})$ and $55-80 \%$ for $\mathrm{Cu}(\mathrm{II})$ system, respectively.

Deprotonation of MLXH at higher pH gives MLX chemical model, Equilibrium (5). MLX could also be formed by the interaction of free metal ion $\mathrm{M}(\mathrm{II})$, primary ligand $(\mathrm{LH})$ and secondary ligand $\left(\mathrm{XH}_{2}\right)$ (cf. Equilibrium (6) and $\mathrm{ML}$ with $\mathrm{XH}_{2}$, Equilibrium (7), in the $\mathrm{pH}$ ranges of 7.0-11.5; $1.5-8.0$ and $2.0-8.5$ with maximum extent of formation varying as low as 15 to max of $90 \%$ for $\mathrm{Co}(\mathrm{II}), 30-80 \%$ for $\mathrm{Ni}(\mathrm{II})$ and $40-90 \%$ for $\mathrm{Cu}(\mathrm{II})$ system, respectively.

The $M L X_{2} \mathrm{H}$ type species might be formed by the interaction of $\mathrm{MLXH}$ with secondary ligand $\mathrm{XH}_{2}$, Equilibrium (8), in the $\mathrm{pH}$ range of 3.0$11.0 ; 1.5-8.0$ and $2.0-9.0$ with max percentage range of $15-40 \% ; 20-90 \%$ and $35-50 \%$ for $\mathrm{Co}(\mathrm{II}), \mathrm{Ni}(\mathrm{II})$ and $\mathrm{Cu}(\mathrm{II})$ system, respectively.

The other species which exists predominantly at higher $\mathrm{pH}$ region is $\mathrm{ML}_{2} \mathrm{X}$. In the present study, $\mathrm{ML}_{2} \mathrm{X}$ might be formed by the interaction of $\mathrm{ML}$ simultaneously with $\mathrm{LH}$ and $\mathrm{XH}_{2}$ (Equilibrium (9)) and MLX with LH (Equilibrium (10)) above the pH of 8.0 for $\mathrm{Co}$ (II); 5.0 for Ni(II) and 6.0 for $\mathrm{Cu}(\mathrm{II})$ with max relative concentrations of 40 to $100 \%$ for all Orn-M(II)-Phen system in PEG-400- and TBAB-water mixture. The formation of these complex species can be represented by the following equilibria.

\begin{tabular}{|lll|}
\hline $\mathrm{M}(\mathrm{II})+\mathrm{LH}+\mathrm{XH}_{2}$ & $\mathrm{MLXH}+2 \mathrm{H}^{+}$ & (4) \\
\hline $\mathrm{MLXH}$ & $\mathrm{MLX}+\mathrm{H}^{+}$ & $(5)$ \\
\hline $\mathrm{M}(\mathrm{II})+\mathrm{LH}+\mathrm{XH}$ & $\mathrm{MLX}+3 \mathrm{H}^{+}$ & $(6)$ \\
$\mathrm{ML}+\mathrm{XH} \mathrm{H}_{2}$ & $\mathrm{MLX}+2 \mathrm{H}^{+}$ & $(7)$ \\
\hline $\mathrm{MLXH}+\mathrm{XH} \mathrm{H}_{2}$ & $\mathrm{MLX}_{2} \mathrm{H}+2 \mathrm{H}^{+}$ & $(8)$ \\
\hline $\mathrm{ML}+\mathrm{LH}+\mathrm{XH}_{2}$ & $\mathrm{ML}_{2} \mathrm{X}+3 \mathrm{H}^{+}$ & $(9)$ \\
\hline $\mathrm{MLX}+\mathrm{LH}$ & $\mathrm{ML} \mathrm{L}_{2} \mathrm{X}+\mathrm{H}^{+}$ & $(10)$ \\
\hline
\end{tabular}

\subsection{Structures of mixed ligand complexes}

The stability of a complex is directly dependent on the nature of the central metal ion (charge density and size) in readily accepting electron pairs from the donor atom, the ligand (its basicity to easily coordinate with metal ion via its electron pairs), the hard-soft interaction of the ligand and metal ion; and the complex formed (chelates vs open chain). Based on the knowledge of lone pair/bond pair interactions to minimize repulsive strain with maximum bond separation and other contributing factors, chemical structures for the mixed ligand complexes were deduced. The rigid framework of Phen and the relative stability of the five member L-ornithine ring complexes with central metal ion could also be considered as contributors to the stability of the synthesized complexes. Considering these, the following most likely octahedral structures [21], corresponding to the $M L X, M L X H, M L_{2} X$ and $M L X_{2} H$ chemical models, are proposed for all the metal ions but $\mathrm{Cu}(\mathrm{II})$ complexes have also Jahn-Teller distorted structure [26] (Fig. 3). 


\section{Conclusion}

In this study, the chemical models refined were only $M L X H, M L X{ }_{2} H, M L X$ and $M_{2} X$ for $\mathrm{Co}(I I), N i(I)$ and $\mathrm{Cu}(I I)$ since the active Orn exists as $\mathrm{LH}_{3}{ }^{2+}, \mathrm{LH}_{2}{ }^{+}$and $\mathrm{LH}$ active forms in the $\mathrm{pH}$ ranges of 2.0-3.5, 2.0-9.0, 8.0-11.0 [50] and Phen as $\mathrm{XH}_{2}{ }^{2+}$ and $\mathrm{XH}^{+}$active forms in the $\mathrm{pH}$ ranges of 1.6-7.0 and 1.48-7.0 [22], respectively. The extra stability of mixed ligand complexes compared to the parent binary complexes was determined based on disproportination constant $(\log X)$ and change in the stability constant $(\Delta \log K)$ of the complexes [26]. This extra stability may be attributed to the interactions outside the coordination sphere, such as the formation of hydrogen bonds between the coordinated ligands, chelate effect, charge neutralisation, the electrostatic interaction between non-coordinated charge groups of the ligands and stacking interactions. Thus, this study threw light on the bioavailability, transport and storage of the metal ions in the biofluids. The less stable binary complexes could easily be bioavailable while the mixed ligand complexes could be stored and transported in the bio-fluids. The sufficiency of the best fit chemical model has been validated by the introduction of pessimistic errors. Pessimistic errors due to change in the concentration of alkali and acids affected the values of the stability constants, standard deviations, and caused rejection of some of the chemical species more significantly than the ligands and metal ions. The linear decrease in the values of stability constants with concentration of surfactants may be ascribed to the synergistic effects of lowered dielectric constant values and destabilising influences of the neutral and cationic surfactants on the positively charged complexes.

\section{Declarations}

\section{Ethics and Consent to Participate}

Not applicable

\section{Consent of interest to publish statement}

Not applicable

\section{Data availability statement}

Any data included in this article are acknowledged and data generated or analysed during this study are included in this to be published article.

\section{Competing interests}

The authors declare that they have no competing interests regarding the publication of this article.

\section{Funding statement}

There has not been any grant received for this work except material support from Andhra University, India.

\section{Author contribution statement}

AGA and GNR: conceived and designed the experiments, contributed data analysis tools; MTN, MLA, BMW, AAM contributed in the data interpretations and development of the manuscript; PS contributed reagents, materials and allow instrument to do with.

\section{Acknowledgements}

One of the authors (A.G) thanks Ministry of Education of the Federal Democratic Republic of Ethiopia, University of Gondar, Ethiopia and School of Chemistry, Andhra University, India.

\section{References}

1. Rao, V. S., Rao, P. S., Srikanth, B., Sastry, C. K. and Rao, G. N. (2009) Speciation of binary complexes of Co(II), Ni(II), $\mathrm{Cu}(\mathrm{II})$ and $\mathrm{Zn}(\mathrm{II})$ with L-aspartic acid in anionic, cationic and neutral micellar medium, Chem. Speciat. Bioavail., 2: 71-80.

2. Zhou, Shi-W., Ma, Yi-B., and Xu, Ming-G. (2009) Ageing of added copper in bentonite without and with humic acid, Chem. Speciat. Bioavail., 21:3, 175-184, DOI:10.3184/095422909X12473330533592. 
3. Mestek, O., Kominkova, J., Santrucek, J., Kacer, P., Malisova, K. and Koplik, R. (2012) Analyses of trace metals, peptide ligands of trace metals and mercury speciation in home prepared bread, Chem. Speciat. Bioavail, 24:2, 79-88, DOI:

10.3184/095422912X13325261626531.

4. Tashakor, M., Yaacob, W.Z.W., Mohamad, H., Ghani, A.A., and Saadati, N. (2014) Assessment of selected sequential extraction and the toxicity characteristic leaching test as indices of metal mobility in serpentinite soils, Chemical Chem. Speciat. Bioavail, 26:3, 139-147, DOI: 10.3184/095422914X14036277112433.

5. Hirpaye, B.Y. and Rao, G.N. (2013) Chemical speciation of 2,3-dihydroxybenzoic acid complexes with some biologically essential metal ions in 1, 2-propanediol-water mixtures, Chem. Speciat. Bioavail., 25:3, 179-186, DOI: 10.3184/095422913X13785645585260.

6. Bendi, R.R., Devi, V.S. and Rao, G.N. (2012) Chemical speciation of ternary complexes of L-dopa and 1,10-phenanthroline with Co(II), $\mathrm{Ni}(\mathrm{II})$ and $\mathrm{Cu}(\mathrm{II})$ in low dielectric media, Chem. Speciat. Bioavail., 24:2, 89-96, DOI: 10.3184/095422912X13324388533472.

7. Prenesti, E., Daniele, P.G., Toso, S., Zelano, V. and Berto, S. (2004) Development of a speciation model for the interpretation of the acidbase properties of grape red wines, Chem. Speciat. Bioavail., 16:1-2, 17-24, DOI: 10.3184/095422904782775081.

8. Rao, R.S. and Rao, G.N. (2005). Computer Applications in Chemistry. Himalaya Publishing House, Mumbai, India.

9. Ramanaiah, M., Goutham Sri, S. and Sailaja, B.B.V. (2013) Effect of non ionic micelles on the chemical speciation of binary complexes of $\mathrm{Pb}(\mathrm{II}), \mathrm{Cd}(\mathrm{II})$ and $\mathrm{Hg}(\mathrm{II})$ with L-phenylalanine, Chem. Speciat. Bioavail., 25:4, 285-290, DOI: 10.3184/095422913X13842645604336.

10. Shaban E. G., Gaber M. Abu El-R., Ola A. Al-G. \& Tarek Y. (2010) Flotation separation of mercury(II) from environmental water samples using thiosemicarbazide derivatives as chelating agents and oleic acid as surfactant, Chem. Speciat. Bioavail., 22:2, 127-134, DOI: 10.3184/095422910X12692736419828.

11. Sakurai, T., Yamauchi, O. and Nakahara, A. (1976) Bull. Chem. Soc. Jpn., 49: 169.

12. Watters, J. I. and Dawitt R. (1960) J. Amer. Chem. Soc., 82: 1333.

13. Esteves, A., Escobar, J., Martinez, J.D., Araujo, M.L., Brito, F., Hernandez, L., Carpio, E.D., and Lubes, V. (2015) Mixed-ligand complex formation equilibria of vanadium(III) with picolinic and dipicolinic acids with some dicarboxylic acids (oxalic, malonic, and phthalic acids) studied in $3.0 \mathrm{M} \mathrm{KCl}$ at $25^{\circ} \mathrm{C}$, Chem. Speciat. Bioavail., 27:1, 15-21, DOI: 10.1080/09542299.2015.1023087.

14. Rao, V.M. Latha, M.P., Rao, T.S. and Rao, G.N (2006) Mixed ligand complexes of toxic metal ions with L-glutamic acid and Lmethionine in ureawater mixtures, Chem. Speciat. Bioavail., 18:4, 143-151, doi.org/10.1080/09542299.2006.11073749.

15. Irving, H.M. and Rossotti, H.S. (1954) The Calculation of Formation Curves of Metal Complexes from pH Titration Curves in Mixed Solvents. J. the Amer. Chem. Soc., 2904-2910. https://doi.org/10.1039/jr9540002904.

16. Mounir, N., Jazouli, H.El., Amine, M.El., Masbouh, F., Kabli, Ait Ichou, H. Y. and Albourine, A. (2007) Potentiometric and quantum studies of the speciation of phenoxyacetic acids in the presence of mercury (II) and of lead (II), Chem. Speciat. Bioavail., 19:2, 45-56, DOI: 10.3184/095422907X211864.

17. Mounir, L.N., Eljazouli, H., Kabli, H., Assabbane, A., Ait Ichoub, Y. and Albourine, A. (2008) Potentiometric examination of ternary complexes of 2,4-D and 2,4-MCPA, components of a weedkiller, with $\mathrm{Cu} 2+, \mathrm{Cd} 2+, \mathrm{Hg} 2+, \mathrm{Pb} 2+$ and $\mathrm{Zn} 2+$, and a quantum approach to their structures, Chem. Speciat. Bioavail., 20:1, 1-11, DOI: 10.3184/095422908X295825.

18. Guerra, E., Martínez, Y., Martinez, J.D., Araujo, M.L., Brito, F., Carpio, E.D., Hernandez L. and Lubes V. (2015) Potentiometric studies on the formation equilibria of ternary complexes of vanadium(III) with cysteine and some amino acids, Chem. Speciat. Bioavail., 27:1, 2228, DOI: 10.1080/09542299.2015.1023088.

19. Nandihalli, U.B. and Rebeiz, C.A., Photodynamic herbicides. 9. Structure activity study of Substituted 1,10-phenanthrolines as potent photodynamic herbicide modulators Pestic. Biochem. Physiol., 1991, 40, 27-46.

20. Chetana, P.R., Rao, R., Saha, S., Policegoudra, R.S., Vijayan, P., Aradhya M.S. (2012) Polyhedron, 48: 43-50.

21. Padmaja, N. and Rao, G.N. (2012) Speciation of ternary complexes of lead(II), cadmium(II) and mercury(II) with L-dopa and phennanthroline in propanediol-water mixtures, Chem. Speciat. Bioavail., 24:4, 234-240, DOI: 10.3184/095422912X13489993038027.

22. Atnafu, G.A., Srinivasu, R., Shyamala, P. and Rao, N.G. (2018) Shift in pKa of 1,10-Phenanthroline in TBAB and PEG-400 Micellar Media: A Potentiometric Study, American Journal of Analytical Chemistry, 9, 397-405, DOI: 10.4236/ajac.2018.99031.

23. Cotton, F. A. and Wilkinson, G. (1972) Advanced Inorganic Chemistry, $3^{\text {rd }}$ Ed., Interscience, 723.

24. McWhinnic, W. R. and Miller, J. D. (1969) Adv. Inorg. Chem. Radiochem., 12: 135.

25. Zhang, Z., Bi, C., Schmitt, S.M., Fan, Y., Dong, L., Zuo, J. and Dou, Q.P (2012) 1,10-Phenanthroline promotes copper complexes into tumor cells and induces apoptosis by inhibiting the proteasome activity. J Biol Inorg Chem. 17:1257-1267. 
26. Atnafu, G.A., Srinivasu, R., Shyamala, P. and Rao, N.G. (2019) Mononuclear Binary Complex Formation Equilibria of L-Ornithine with Biologically Essential Metals in TBAB Micellar Media, Asian J. of Chem.; Vol. 31, No. 6, 1383-1388, Doi.org/10.14233/ajchem.2019.21979.

27. Rose C., Michalak A., Pannunzio P., Therrien G., Quack G., Kircheis G., Butterworth R.F. L-ornithine-I-aspartate in experimental portalsystemic encephalopathy: Therapeutic efficacy and mechanism of action. Metab. Brain Dis. 1998;13:147-157. doi: 10.1023/A:1020613314572.

28. Gran, G., 1952. Determination of the Equivalence Point in Potentiometric Titrations, Part II. Analyst, v. 77, pp. 661-671.

29. Asagba, E.U., Okieimen F.E. and Osokpor, J. (2007) Screening and speciation of heavy metal contaminated soil from an automobile spare-parts market, Chem. Speciat. Bioavail., 19:1, 9-15, DOI: 10.3184/095422907X198022.

30. [30]. Veeraswami, B., Bhushanavathi, P., Viplavaprasad, U. and Rao, G.N. (2014) Speciation of ternary complexes of Ca(II), Zn(II) and $\mathrm{Mn}$ (II) with L-proline and L-valine in acetonitrile-water mixtures, Chem. Speciat. Bioavail., 26:1, 13-20, DOI: 10.3184/095422914X13884191074459.

31. Kiptoo, J.K. and Ngila, J.C. (2005) Voltammetric evaluation of binding abilities of tannery effluents by competing ligand exchange method using model solutions of $\mathrm{Cr}(\mathrm{VI}), \mathrm{Ni}(\mathrm{II}), \mathrm{Cu}(\mathrm{II})$ and $\mathrm{Pb}(\mathrm{II})$, Chem. Speciat. Bioavail., 17:3, 103-108, DOI: 10.3184/095422905782774900.

32. Rao, G.N. (1989) Complex equilibria of some biologically important metal ions in aqua-organic media, PhD thesis, Andhra University, India.

33. Sylva, R.N. and Davidson, M.R. (1979) The hydrolysis of metal ions. Part 2. Dioxouranium(VI) J. Chem. Soc. Dalton Trans $232,465$.

34. Shoukry, M.M. and Ezzat, S.M.T. (2015) Speciation studies of mono- and binuclear Pd(II) complexes involving mixed nitrogen-sulfur donor ligand and 4,4'-bipiperidine as a linker, J. Coord. Chem., 68:17-18, 3135-3147, DOI: 10.1080/00958972.2015.1043909.

35. Sakurai, T.; Yamauchi, O.; Nakahara, A. Solution Equilibria of Ternary a-Amino Acid-Copper(II) Complexes with Electrostatic Ligand-Ligand Interactions. Bull. Chem. Soc. Jpn.1978, 51, 3203-3208.

36. Hadgu, B. H., Sailaja, B. B. V. and Rao G. N. (2015) Chemical speciation of ternary complexes of L-Ornithine and Ethylenediamine with some metal ions in low dielectric media, Der Pharma Chem., 7(5) 147-156.

37. Moussa, N.M., Marafie, H.M., El-Ezaby, M.S. and Rashad, M. (1987) Polyhedron, 6: 1477.

38. Shehata, M.R. Shoukry M.M. and Barakat, M.H. (2004) Coordination properties of 6-aminopenicillanic acid: binary and ternary complexes involving biorelevant ligands, J. Coord. Chem., 57:16, 1369-1386, DOI: 10.1080/0095897042000261935.

39. Rao, G. N. and Murthy, V. L. S. N. (2004) Effect of dielectric constant of medium on protonation equilibria of L-glutamine and succinic acid. J. Indian Chem. Soc., 81: 42.

40. Rao, G.N. and Sudarsan, K.G. (2006) Effect of micelles on speciation of ternary complexes of nickel(II) with L-arginine and L-histidine, Chem. Speciat. Bioavail., 18:2, 71-76, http://dx.doi.org/10.3184/095422906782146267.

41. Raju, S., Naik, K.B.K, Kumar, B.A. and Rao, G.N (2012) Speciation of complexes of Co (II), Ni (II) and Cu (II) with L-histidine in dioxanwater mixtures, Chem. Speciat. Bioavail., 24:1, 46-52, DOI: 10.3184/095422912X13257797981584.

42. Singh, J. and Kalamdhad, A.S. (2013) Bioavailability and leachability of heavy metals during water hyacinth composting, Chem. Speciat. Bioavail., 25:1, 1-14, DOI: 10.3184/095422913X13584520294651.

43. Pyreu, D., Gridchin, Sergei and Kozlovskii, E. (2016) Mixed ligand complexes of copper(II) iminodiacetate with di- and tripeptides in solution, J. Coord. Chem., 69:22, 3424-3435, DOI: 10.1080/00958972.2016.1230205.

44. Griesser, R. and Sigel, H. (1970) Inorg. Chem., 9: 1238.

45. Griesser, R. and Sigel, H. (1971) Inorg. Chem., 10: 2229.

46. Griesser, R. and Sigel, H. (1974) Inorg. Chem., 13: 462.

47. Sigel, H. Huber, P. R. Greisser, R. and Prijs, B. (1974) Inorg. Chem., 12: 1198.

48. Kumar, B.A, Naik, K.B.K., Raju, S. and Rao, G.N. (2012) Speciation studies of ternary complexes of some essential divalent metal ions with Lhistidine and L-glutamic acid in DMSO-water mixtures, Chem. Speciat. Bioavail., 24:3, 159-166,

http://dx.doi.org/10.3184/095422912X13409979284127.

49. Sakurai, T. Yamauchi, O. and Nakahara, A. (1977) Bull. Chem. Soc. Jpn., 50: 1776.

50. Srinivasu, R., Assefa, A.G., Shyamala, P. and Rao, G.N. (2019) Effect of ionic and non-ionic micelles on protonation equilibria of Lornithine: a potentiometric study, Journal of Emerging Technologies and Innovative Research, Volume 6, Issue 3, ISSN-2349-5162. 


\section{Figures}
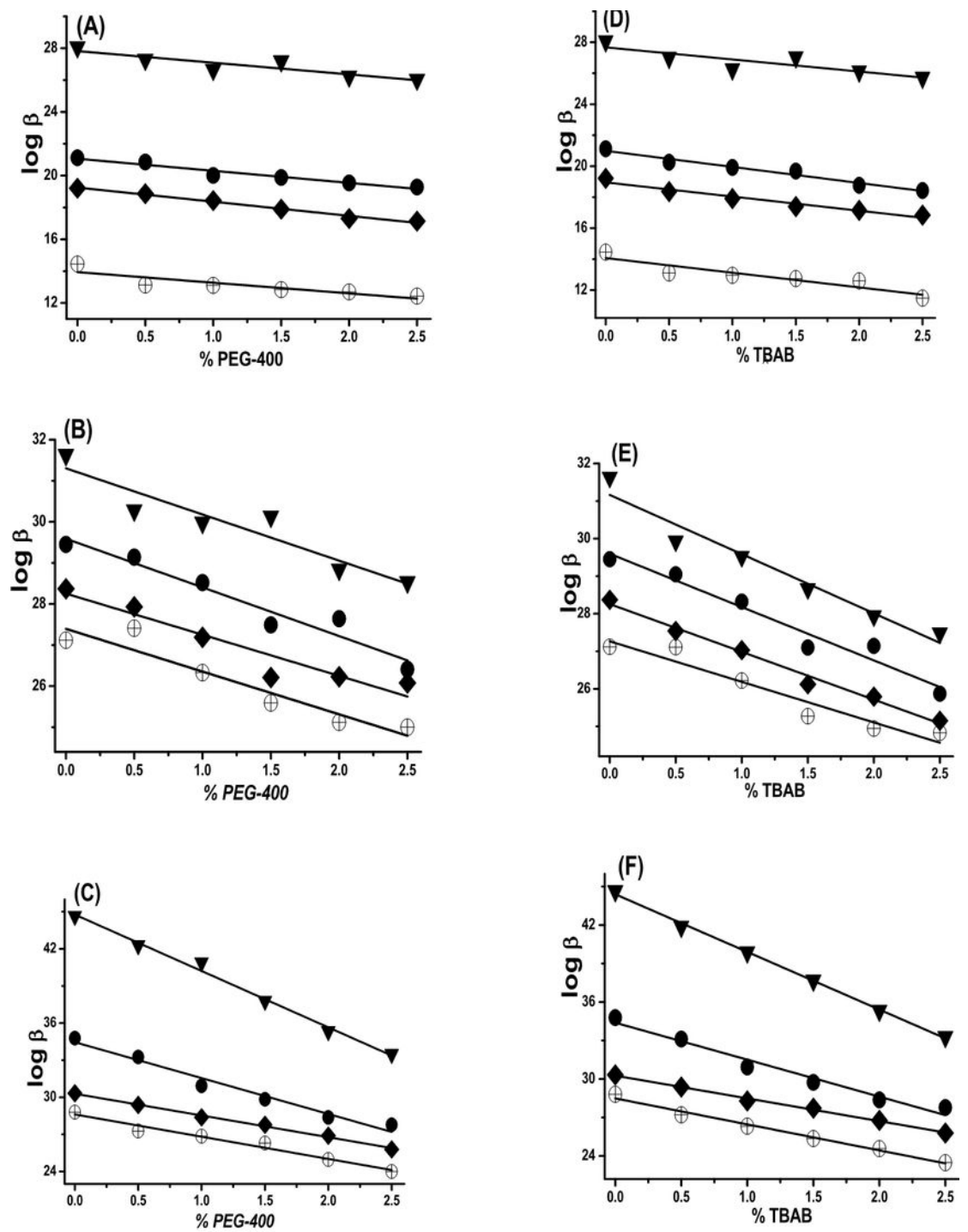

\section{Figure 1}

Variation of stability constant (log $\beta$ ) values of Orn-M(II)-Phen complexes of (A), (D) Co(II), (B), (E) Ni(II) and (C), (F) Cu(II) in PEG-water (A-

C) and TBAB-water (D-F) mixtures with percentage of surfactants: $(\otimes) \log \beta M L X,(\square) \log \beta M L X H,(\bullet) \log \beta M L 2 X$ and $(\triangleleft) \log \beta M L X 2 H$. 

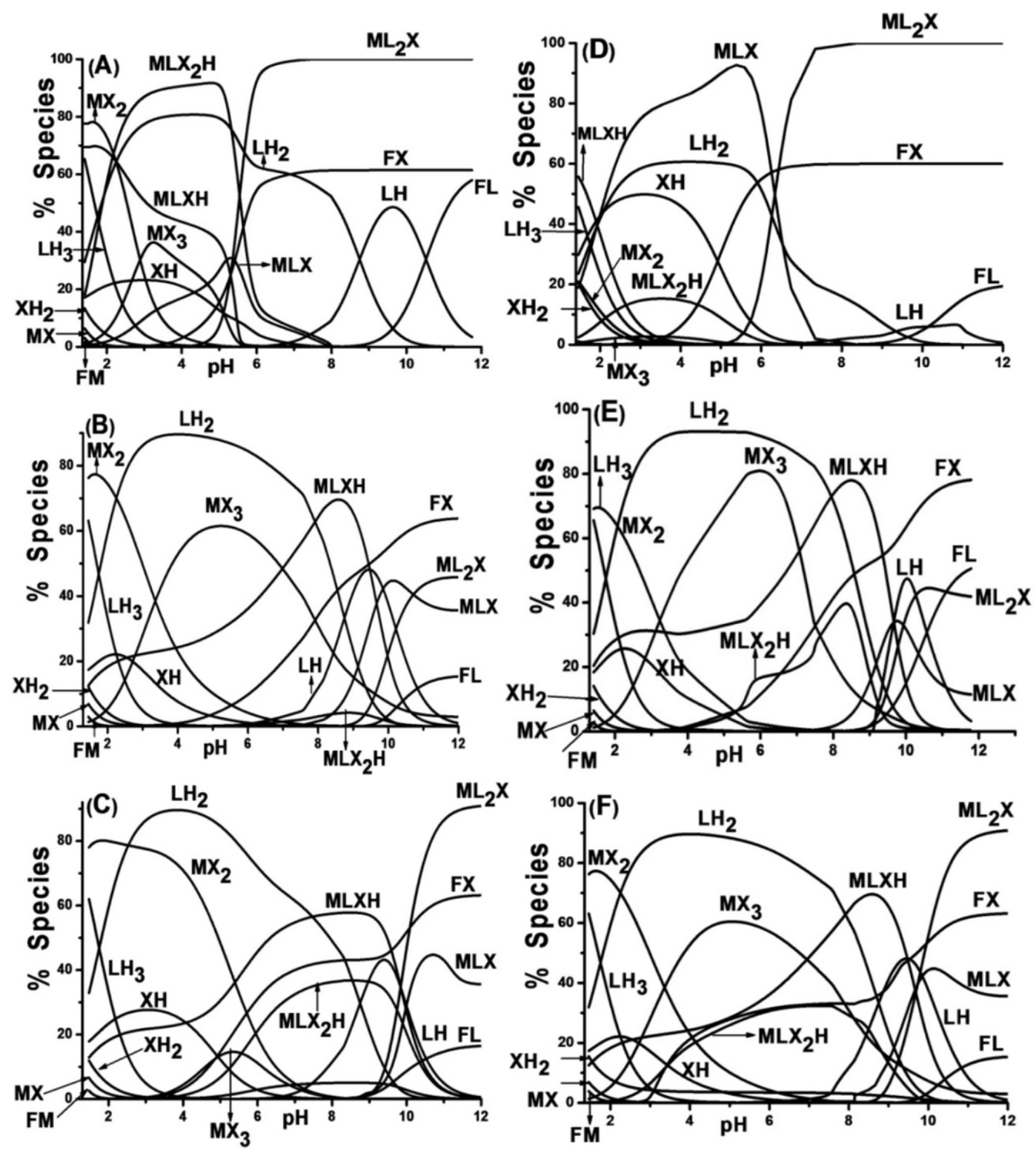

Figure 2

Concentration distribution diagrams of Orn-Co(II)-Phen complexes in $1.5 \%(\mathrm{v} / \mathrm{v})$ aqueous PEG-400 (A-C)- and TBAB (D-F). (A) and (D) are for $\mathrm{Ni}(\mathrm{II}) ;(\mathrm{B})$ and $(\mathrm{E})$ for $\mathrm{Cu}(\mathrm{II})$ and $(\mathrm{C})$ and $(\mathrm{F})$ for $\mathrm{Co}(\mathrm{II})$. The analytical concentrations of metal and ligand are: $\mathrm{M}(\mathrm{II}): \sim 0.1$ and $\mathrm{L}$ and $\mathrm{X}$ : $\sim 0.05$. (mol L-1). 


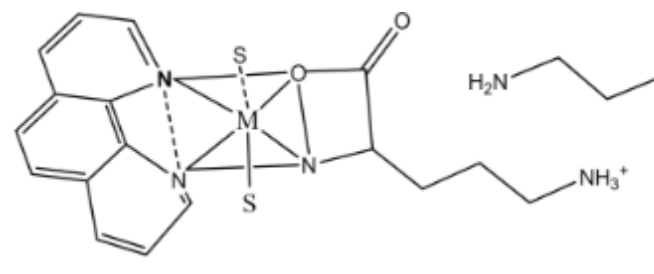

(a) MLXH

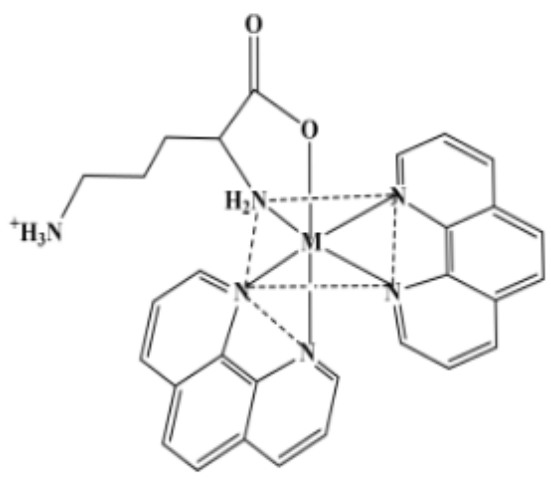

(c) $\mathrm{MLX}_{2} \mathrm{H}$

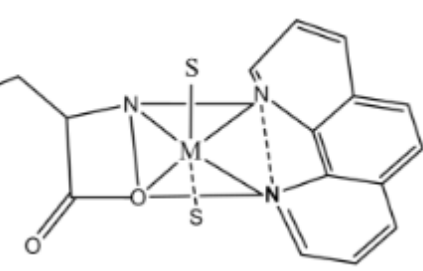

(b) MLX

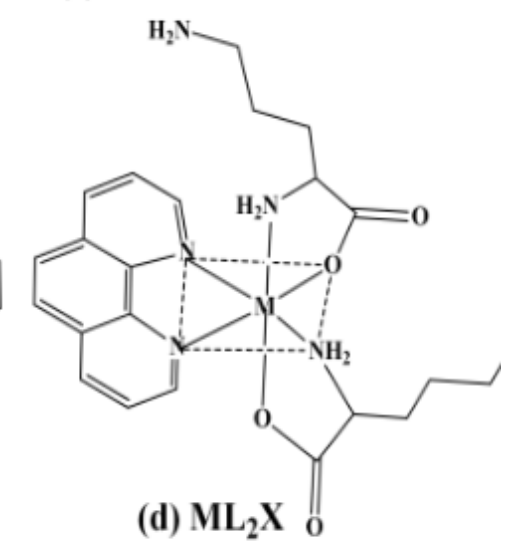

Figure 3

Suggested structures for the Orn-M(II)-Phen complexes, where $\mathrm{S}$ is either solvent of water molecule and $\mathrm{M}$ stands for $\mathrm{Co}(\mathrm{II}), \mathrm{Ni}(\mathrm{II})$ or $\mathrm{Cu}(\mathrm{II})$. 